\title{
Extracranial Internal Carotid Artery (ICA) Aneurysm Repair and End to End Anastamosis of the Artery
}

\author{
Murali P. Vettath1 ${ }^{*}$, Madhu Ravisankar ${ }^{2}$, Kannan Av², Nitin Gangadharan ${ }^{2}$ \\ ${ }^{1}$ Cardiovascular and Thoracic Centre, MEITRA Hospital, Kozhikode, India \\ ${ }^{2}$ Department of Cardiovascular and Thoracic Surgery, MEITRA Hospital, Kozhikode, India \\ Email: *murali.vettath@gmail.com, drmadhu.r@hotmail.com
}

How to cite this paper: Vettath, M.P., Ravisankar, M., Av, K. and Gangadharan, N. (2019) Extracranial Internal Carotid Artery (ICA) Aneurysm Repair and End to End Anastamosis of the Artery. World Journal of Cardiovascular Diseases, 9, 295-299. https://doi.org/10.4236/wjcd.2019.94025

Received: March 3, 2019

Accepted: April 21, 2019

Published: April 24, 2019

Copyright () 2019 by author(s) and Scientific Research Publishing Inc. This work is licensed under the Creative Commons Attribution International License (CC BY 4.0).

http://creativecommons.org/licenses/by/4.0/

\begin{abstract}
We present a case of extracranial internal carotid artery (ICA) aneurysm, which presented as an inflammatory submandibular swelling in the upper part of the right side of the neck. The lack of frank pulsatility and signs of inflammation though was a bit confusing, the Doppler and CT angiogram clinched the diagnosis. We were able to surgically resect and reform the ICA using the native vessel itself, which is an unusual technique, which we thought was worth presenting.
\end{abstract}

\section{Keywords}

Internal Carotid Artery, Aneurysm Repair

\begin{abstract}
Extracranial carotid artery aneurysms are uncommon and occur in a broad range of patients due to many etiologies. True aneurysms involving all layers of the carotid arterial wall and false aneurysms both occur. Overall, extracranial carotid artery aneurysm accounts for less than 1 percent of all arterial aneurysms and approximately 4 percent of peripheral artery aneurysms [1] [2] [3]. Repair of extracranial carotid artery aneurysm represents 0.2 to 5 percent of carotid procedures depending upon the reporting institution [4]. We present a case of extracranial ICA aneurysm, successfully operated in our institution with resection and end to end anastomosis of the same artery.
\end{abstract}

\section{Case Report}

A 37-year-old male, presenting with a painful swelling on the right side of the 
neck, with the deviation of the tongue to the opposite side is presented. He had a Doppler test done elsewhere which showed aneurysmal mass at the level of right carotid bifurcation extending superiorly with displacement of neck vessels. Heterogeneous signal on Doppler, suggestive of aneurysm (with active flow) noted in the upper neck originating from the distal cervical ICA which is placed posteriorly in the carotid space compressing and displacing proximal ICA and its branches. CT angiogram confirmed the diagnosis (Photo A), showing the aneurysmal sac of the cervical ICA and the entry and exit vessels from it.

He underwent resection of right Internal Carotid Artery Aneurysm and end to end anastomosis of the internal carotid artery segments. The incision extended from the angle of the mandible to the sternal notch parallel to right sternocleidomastoid muscle. The swelling was $5 \times 5 \times 6 \mathrm{~cm}$ and the aneurysm was stretching both the external and internal carotid away from each other. Internal carotid artery was seen extending along the aneurysm and draining at the superior pole of the aneurysm (Photo B-1). This part had to be dissected from under the mandible to visualize the distal portion of the cervical segment of the internal carotid artery (Photo B-2). The common carotid artery was exposed. The external carotid was seen plastered and running medial to the aneurysm. The hypoglossal nerve was found stretched across the aneurysm. The exit limb of the internal carotid artery was found at the superior pole of the aneurysm. As the sump pressure of the distal end of ICA was less than $8 \mathrm{~mm}$ of $\mathrm{Hg}$ it was decided to insert a shunt into the internal carotid artery. The proximal limb of the shunt was inserted into the Internal Carotid and the distal end was inserted into the

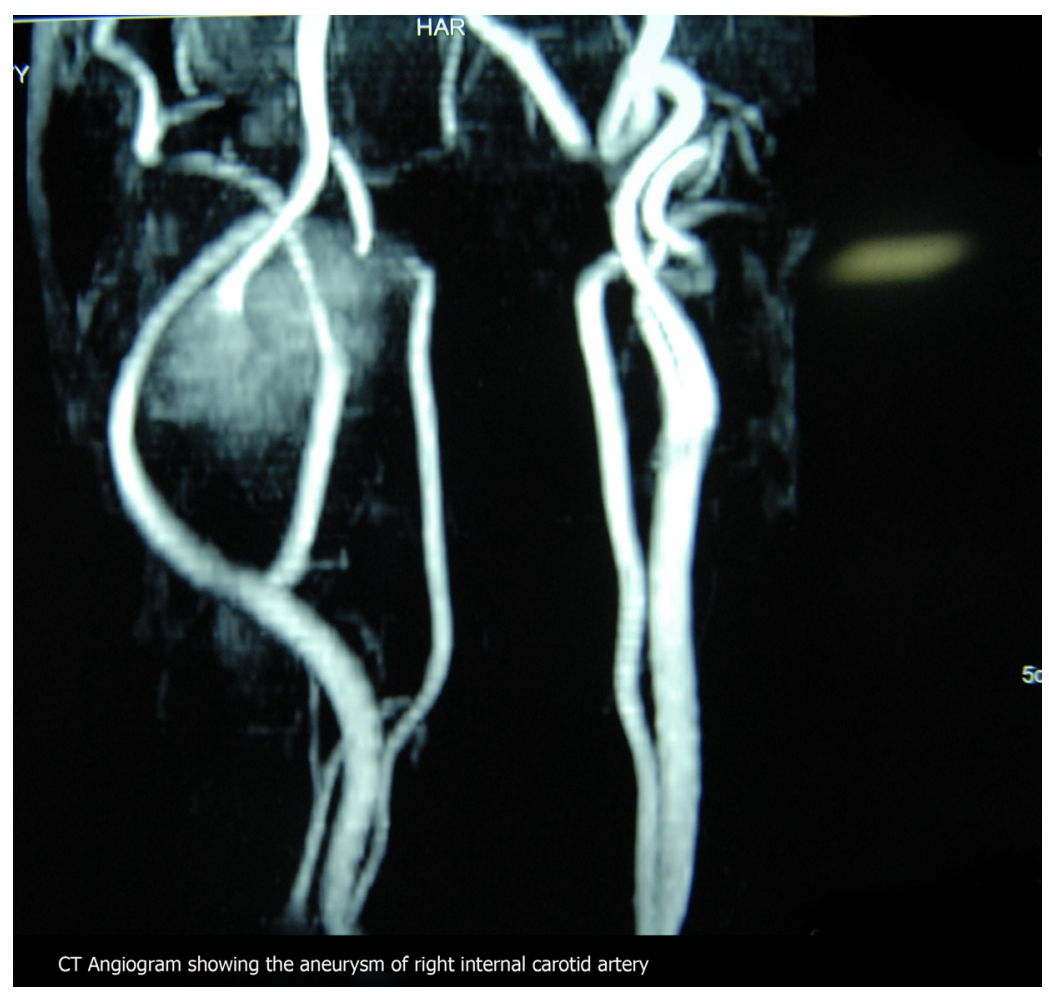

Photo A. CT angiogram showing the aneurysm of the left ICA. 

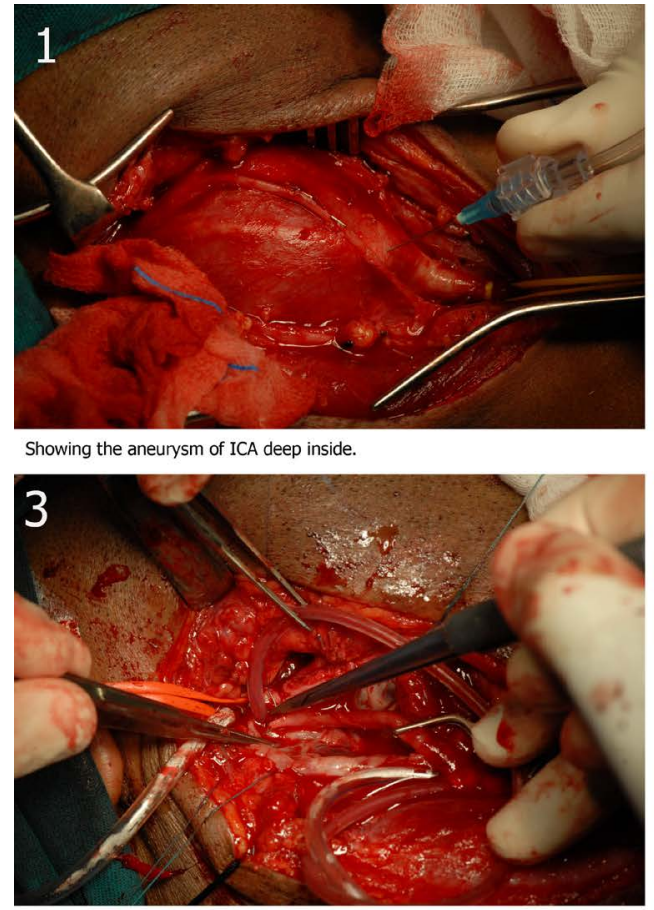

The internal carotid artery disconnected from the aneurysm and anastomosed to the distal end of the ICA.

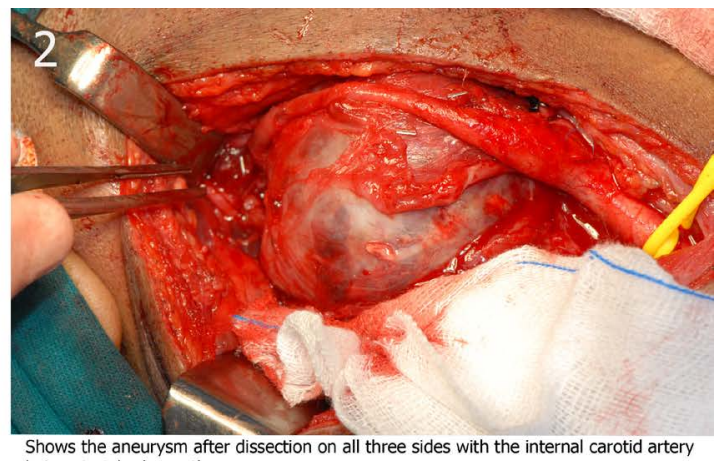
being stretched over the aneurysm.

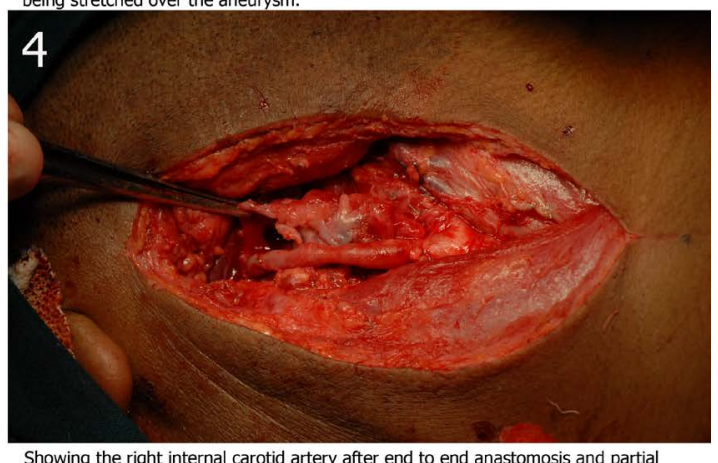

Showing the right internal carotid artery after end to end anastomosis and partial excision of the aneurysm sac.

Photo B. The surgical photographs showing each stage of the procedure as written under each photo.

distal part of the internal carotid after opening the aneurysm. The proximal limb of the internal carotid artery was disconnected from the aneurysm at its entry. This limb was then anastomosed to the area of distal internal carotid artery through which the shunt had been inserted distally (Photo B-3). The anastomosis was performed using 6.0 polypropylene suture (Photo B-4). The shunt removed. Hemostasis attained and wound sutured in layers with a drain.

The patient was shifted to ICU in a stable hemodynamic condition. He had an uneventful post-operative stay in ICU and was shifted to the room on the third postoperative day. He was later discharged in good health. He was reviewed after one year and was in perfect health.

\section{Discussion}

Carotid artery aneurysms have various aetiologies and represent a taxing pathology with limited expertise and familiarity. The most common cause of extra cranial carotid artery aneurysms is atherosclerosis. These aneurysms tend to be fusiform and are almost always associated with arterial hypertension. Extra cranial carotid aneurysm repair comprises $0.1 \%$ to $2 \%$ of all carotid procedures [5] [6]. The high incidence of cranial nerve compression and cerebrovascular events through embolization in untreated patients (68\%) justifies invasive management for both symptomatic and asymptomatic carotid aneurysms [7]. Haemorrhage has also been seen as a complication of these aneurysms, although rupture remains uncommon. The surgical techniques applied to the management of extra cranial carotid aneurysms are ligation (or angiographic occlusion), 
endoaneurysmoraphy, resection with primary anastomosis, resection with graft replacement, or stent grafting. In the era of endovascular surgery, techniques used for occlusive disease are extrapolated as minimally invasive alternatives to conventional surgical treatment of extra cranial carotid artery aneurysms. The combined stroke and mortality rate of surgical reconstruction reported by the Texas Heart Institute was 9\% [8]. They described a partial aneurysmectomy and patch closure of a large fusiform aneurysm involving the carotid bifurcation. This approach avoids extensive dissection of the posterior wall of the aneurysm, reducing the rate of cranial nerve dysfunction to 6\%. McCann et al. [9] showed a stroke risk of $25 \%$ and a mortality rate of $20 \%$ in the follow-up of ICA ligation. A meta-analysis by Roset et al. [10] revealed a $1.2 \%$ mortality risk and a $6 \%$ stroke risk.

Long-term results for carotid aneurysm repair using stent grafts have not been established. Zhou et al. [8] reported a decrease in the 30-day stroke/death rate from $14 \%$ to $5 \%$ during a 19 -year period with the introduction of endovascular techniques. Endovascular interventions reduce the risk of cranial nerve injury, can be done without general anaesthesia, are useful for distal lesions where surgical exposure is difficult, are associated with shorter hospital lengths of stay, and have lower morbidity and mortality rates.

\section{Conclusion}

Extracranial ICA aneurysm though is rare. We present the patient presented as a submandibular swelling with signs of inflammation. Luckily it was not incised by the local medical center as they suspected it to be an aneurysm, though it was not pulsatile. In fact on presentation, it was a tense painful swelling. Luckily we could come up with the diagnosis with Doppler and confirmed the anatomy by CT angiogram and proceed with surgery. Though resection and interposition graft were recommended, we could use the native ICA and reform the artery without any artificial graft.

\section{Conflicts of Interest}

The author declares no conflicts of interest regarding the publication of this paper.

\section{References}

[1] El-Sabrout, R. and Cooley, D.A. (2000) Extracranial Carotid Artery Aneurysms: Texas Heart Institute Experience. Journal of Vascular Surgery, 31, 702-712. https://doi.org/10.1067/mva.2000.104101

[2] Welling, R.E., Taha, A., Goel, T., et al. (1983) Extracranial Carotid Artery Aneurysms. Surgery, 93, 319.

[3] McCollum, C.H., Wheeler, W.G., Noon, G.P. and DeBakey, M.E. (1979) Aneurysms of the Extracranial Carotid Artery. Twenty-One Years' Experience. American Jour nal of Surgery, 137, 196-200. https://doi.org/10.1016/0002-9610(79)90144-2

[4] Garg, K., Rockman, C.B., Lee, V., et al. (2012) Presentation and Management of Carotid Artery Aneurysms and Pseudoaneurysms. Journal of Vascular Surgery, 55, 
1618-1622. https://doi.org/10.1016/j.jvs.2011.12.054

[5] Welling, R.E., Taha, A., Goel, T., Cranley, J., Krause, R., Hafner, C., et al. (1983) Extracranial Carotid Artery Aneurysms. Surgery, 93, 319-323.

[6] Rhodes, E.L., Stanley, J.C., Hoffman, G.L., Cronenwett, J.L. and Fry, W.J. (1976) Aneurysms of Extracranial Carotid Arteries. Archives of Surgery, 111, 339-343. https://doi.org/10.1001/archsurg.1976.01360220035006

[7] Preston Flanigan, D. (2013) Aneurysms of the peripheral Arteries. In: Moore, W., Ed., Vascular and Endovascular Surgery: A Comprehensive Review, 8th Edition, Elsevier, Philadelphia, 708-720.

[8] Zhou W., Lin, P.H., Bush, R.L., Peden, E., Guerrero, M.A., Terramani, T., et al. (2006) Carotid Artery Aneurysm: Evolution of Management over Two Decades. Journal of Vascular Surgery, 43, 493-496. https://doi.org/10.1016/j.jvs.2005.11.023

[9] McCann, R.L. (1990) Basic Data Related to Peripheral Artery Aneurysms. Annals of Vascular Surgery, 4, 411-444. https://doi.org/10.1007/BF02000509

[10] Rosset, E., Albertini, J.N., Magnan, P.E., Ede, B., Thomassin, J.M. and Branchereau, A. (2000) Surgical Treatment of Extracranial Internal Carotid Artery Aneurysms. Journal of Vascular Surgery, 31, 713-723. https://doi.org/10.1067/mva.2000.104102 